\title{
Towards a sustainable spatial planning and development in Greek islands and highlands
}

\author{
E. Beriatos \\ Department of Planning and Regional Development, \\ School of Engineering, University of Thessaly, Greece
}

\begin{abstract}
Highlands and islands are the underdeveloped and marginalized areas of Greece in which a series of crucial planning and development problems occur. The paper attempts a description of those areas not only in terms of physical spatial structure but also in terms of socio-economic dependence from the developed 'integrated'- regions of the country (urban and industrial areas). It is essential to describe the structural features of these areas in order to understand their true needs, so that efforts can be made towards the creation of a planning model, which will integrate these areas, using the benefits provided by new technologies. To this purpose the paper investigates an implementation example (pilot project), in the central Mediterranean Sea, which has been developed in the framework of EU trans-national cooperation programs, in the field of spatial and environmental planning matters in order to show that ITC advanced technologies can reinforce participatory planning processes in the new 'network society'.

Keywords: mountainous and island regions, participatory planning, tele-informatics, networks.
\end{abstract}

\section{Introductory remark}

Based on its specific geomorphological characteristics, Greece is characterized by an internal intense spatial fragmentation and discontinuity, with a variety of highlands and islands. Greece, as indicated by various quantitative indicators, is the most mountainous country and at the same time the country with the largest number of islands in Europe, since there are even islands with significant mountainous areas. Nevertheless, Greece does not have until now an integrated policy aiming at the development of mountainous and island regions. The country's geographic location places it on a 'geographic crossroad' but at 
the same time, also on a 'margin'. These differences, that compose Greece's identity, are at the same time its strengths and weaknesses, its disadvantages but also its comparative advantages. These mountainous and island regions are a non-integrated part of their country's national territory, that are marginalized, isolated and depended, all problems which are not always linked to geographic causes.

\section{Main features of the Greek Highlands and Islands}

The Hellenic mountainous regions are a combination of extended areas characterized by a variety of fragile and sensitive natural and human habitats. From a physical and geographical point of view, Greek mountains are an important source of natural resources (water, forestry products), energy and biological diversity reserves. Moreover, the intense fluctuations of the relief create a variety of climatic zones, and consequently, a wide variety of habitats, occurring in a limited space area. On the other hand, the potential hazards from erosion and land sliding are more intense in highland areas [6].

However, the most intense problem threatening the Greek mountainous areas (the largest part of which is not included in the country's development axis i.e integrated areas) is the population decrease, not only in relative terms (as a percentage of the total country's population) but also in absolute terms, resulting in the creation of an extremely fragile socio-economic grid.

This aforementioned threat is not the only one existing in mountainous regions, since the latter are confronted with substantial hazards and challenges directly linked to the processes for their integration into the current socioeconomic, technological and environmental developments. From a human activities' and interventions' perspective, tourism is undoubtedly the main activity that can present a possible threat for the future. Indeed, Greece seems to follow west European countries in their tourism development model [8]. So, after the island and coastal areas, the national tourism industry is currently "winning over" and "overwhelming" Greek mountainous areas, with the construction of skiing centers and other related infrastructure, in great numbers. This results in a progressive "urbanization of the highlands", which will entail important structural changes in the operation, use and management of the mountainous regions of the country.

Moreover, another threat for the mountainous areas originates from the construction of infrastructure works (mainly road networks) aiming to diminish their geographic isolation. This consists, undoubtedly, a true need for mountainous areas but also an intense threat. This occurs because their isolation has always been the limiting factor to their development, but also the main reason that has substantially contributed to the preservation of a valuable and (at least until now) pristine natural environment. Therefore, we should wander whether the construction of new modern road networks does not only contribute to the increase of human and goods transportation, but also to the decrease of their "hardly transferable" comparative assets and advantage, namely their natural environment. 
On the other hand Greece is the country with the largest number of islands. With a plethora of inhabited islands and a very large number of uninhabited ones, Greece is the first country in the Mediterranean with the highest number of islands, as a percentage of its total surface area and total national population. Its islands correspond to a $19.1 \%$ of the total national surface area and to a $14 \%$ of the total national population, whereas for Italy, with only 2 very large islands, these percentages amount to around $16.7 \%$ and $10 \%$, respectively. In absolute terms, Greece comes second (after Italy), with all the other countries following further behind.

Table 1: $\quad$ Surface area of Islands in Mediterranean Countries.

\begin{tabular}{|l|l|c|}
\hline Countries & surface area $\left.\mathbf{( k m}^{\mathbf{2}}\right)$ & $\begin{array}{l}\text { \% of the total national } \\
\text { surface area }\end{array}$ \\
\hline Spain & 5,000 & 1.0 \\
\hline France & 8,700 & 1.6 \\
\hline Italy & 50,200 & 16.7 \\
\hline Malta & 300 & 100.0 \\
\hline Tunisia & 700 & 0.4 \\
\hline Yugoslavia & 3,200 & 1.2 \\
\hline Turkey & 500 & 0.1 \\
\hline Greece & 25,100 & 19.1 \\
\hline Cyprus & 9,200 & 100.0 \\
\hline
\end{tabular}

Source: E.Y. Kolodny: La population des iles de la Grece [2].

Greek islands are characterized by their high spatial dispersion and their medium sizes. Over $60 \%$ of Greek islands have a surface area of less than $100 \mathrm{~km}^{2}$. This is compensated by their proximity to the mainland, which surrounds the Greek seas, mainly in the case of the Aegean archipelagos, as well as by the geomorphological and climatic coherence of the various island areas.

All the above, without prejudice to the fact that there are indeed islands "lost" in the Greek seas, which are truly remote places in "the very end of the world", as it is commonly said. Thus, the situation of Greek islands could be addressed and seen from various viewpoints, and this is exactly what constitutes their biggest particularity. Islands constitute a substantial supplement and a natural extension of the Greek mainland, and at the same time, a conglomerate of various different "micro-worlds" that are formulated in island complexes.

The term "island" has always been considered as a synonym to the term "isolation". However, islands are not always characterized by isolation. Specifically, in the case of Greece and further in the past, the island character of the country was considered positive. The sea was an element of connectivity and communication with the rest of the world and not an element of separation. The fact that the sea served (at least until the beginning of the $20^{\text {th }}$ century) as a route of communication, is proved by the existing of a very dense network of maritime transportation lines, even along the coastal line of the mainland. Therefore, the geographic location of the islands and the fact that they were 
surrounded by water was not a limiting factor to their accessibility. On the contrary, the problems islands face have been intensified today due to their socio-economic dependence to the mainland, with all the relative consequences that this may entail (immigration, radial transportation networks, lack of intraisland connections, like in the case of the Cyclades complex etc.).

The spatial organization of the Greek island areas today expresses this exact dependence to the center that has been developed mainly during the post-war period. This is also revealed, in a very effective manner, by all data related to the occurrence and formulation of human presence, in older times with even harder living conditions.

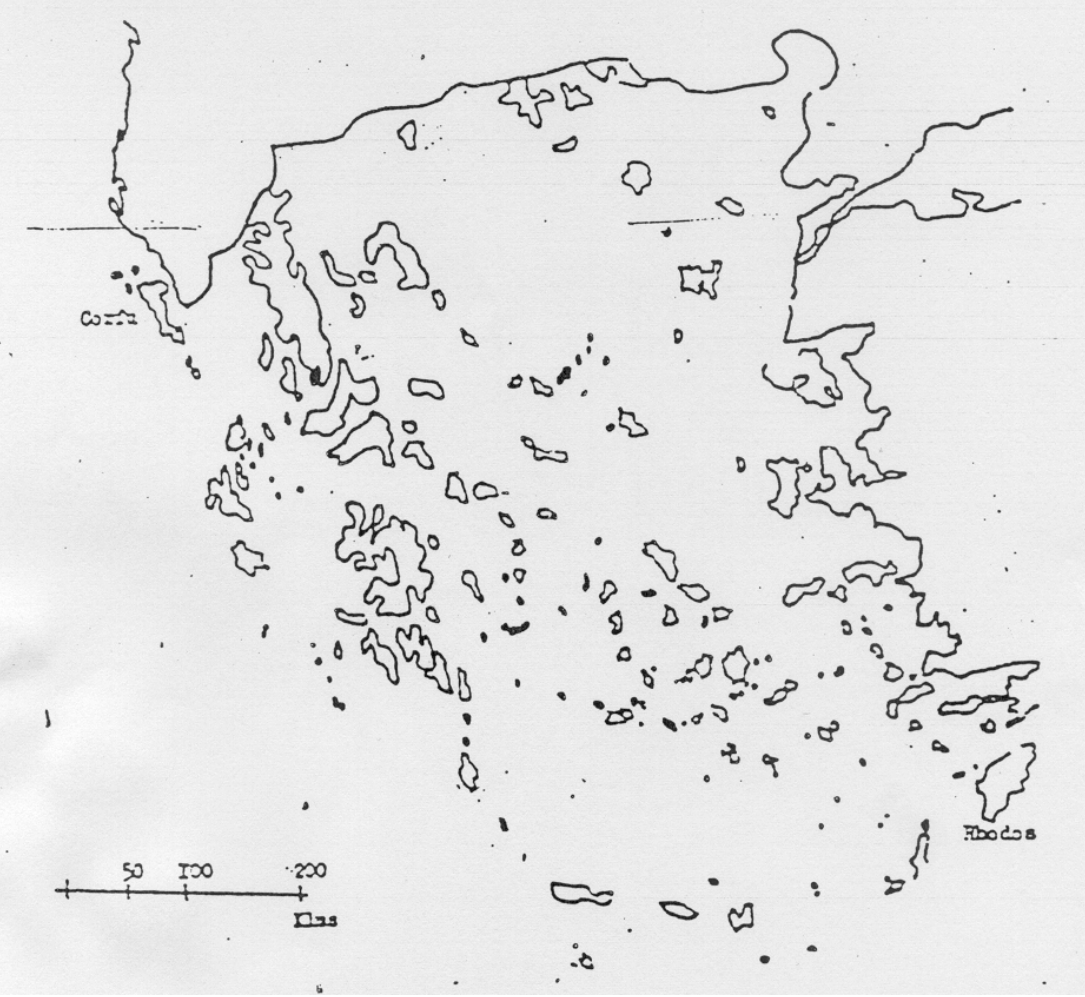

Figure 1: Islands and Highlands in Greece. Source: Mit. Mitropoulos, "Communications Technology and the Organisation of Space" [3]. Remark: Coastline of the mainland is eliminated / Mountain tops above $1000 \mathrm{~m}$ altitude.

\section{Towards a new model of sustainable spatial planning: a telematic network for mountainous and island regions}

According to French philosopher H. Lefevre, space and its social dimension constitutes a productive force, inter alia, for human development. Spatial 
organization or, in other words, the "production" of space, to a great extent, depends on the available technological means that each society has at its disposal. The scientific and technological developments of recent decades have resulted in the rapid growth of telecommunications and information technology sciences. It is the combination of these two sectors that has resulted in the creation of a new scientific hybrid known as "telematics" which has greatly revolutionized the process of economic and social development.

In view of these developments, the meaning and concept of space have undergone a radical transformation. The term 'space' seems to increasingly signify "relation" as opposed to "location". The structure of space has acquired a new dynamic, as spatial planning is now based on the use of networks in which the flow of materials and mainly information prevails. These networks reduce and even abolish distance as well as improve accessibility. At the same time, they create a new space which all those connected to the network come into contact with, the so-called cyberspace. The spatial foundations of society, its "space" in other words, is no longer "sites" and "areas" but networks. The growth of network society constitutes a new and significant parameter throughout the various levels of spatial planning: local, regional, national and global.

According to Manuel Castells [1], the emergence of network society is already a fact. In such a society, the concepts of space, proximity and transportation are reversed as permanent inhabitants who are connected -in the sense that they are "housed" in the network- will be able to travel freely due to this connection, whereas those excluded from the network (and society) will become contemporary "nomads" and will therefore find themselves isolated and stationary in one location (in the margin).

In countries such as Greece, where the natural environment is greatly characterized by discontinuity and fragmentation, cyberspace comes to fill the gap and provide a substitute by undertaking various functions of physical space.

The island and mountainous regions of Greece constitute ideal areas for the implementation of the systems and methods that will promote the complementary functions of physical and "virtual" world. The policy of spatial planning at a national level would have to take this parameter into consideration for various reasons. The most important ones are the reinforcement of decentralization and the reduction of the cost of infrastructure. Therefore a planning model based on the recent technological achievements in the field of transportation, telecommunication and informatics is needed. To this purpose it is necessary to examine the possibility of establishing a system of distant procedures in order to overcome accessibility obstacles due to the lack of transport infrastructures and the lack of business activities.

Indeed, the economic and social services that could be provided by teleinformatics, reduce the dependence from the center and the respective movements from the periphery to the center. On the other hand, the planning and construction of transportation infrastructure (roads, railways etc), throughout the Greek territory, can be very costly due to Greece's great geomorphological diversity. 
The development of a model for spatial organization using contemporary telematic technology has some specific requirements, such as:

The classification of areas based on spatial and environmental criteria. Thus, the following categories emerge:

a. Categories of areas according to the degree of use exploitation or urbanization of land.

b. Categories of areas according to the condition of their natural environment.

c. Categories of areas according to their accessibility and the type of transportation.

The creation of new organizational mechanisms within the existing institutional structures, at a national and local authority level, equipped with the necessary material and technical means, based on the latest technological advances. The cost is not significant compared to the resulting benefit.

The acquisition of the know-how required for the operation of the system, which is directly related to the availability of adequate human resources, from a quantitative but also qualitative point of view.

The geographic field of application of such a telematic network could initially encompass the most isolated regions of the Greek territory. More specifically, it should encompass the 40 smallest Greek islands with a surface area up to $50 \mathrm{~km}^{2}$ (of the total 150 inhabited Greek islands) as well as all settlements located at an altitude over 1000 meters (see map Islands and Highlands). On a second stage, it could be expanded so as to cover all islands and areas with an altitude of over 600 meters.

The thematic field of application could include:

a. Administrative services (provision of certificates etc.) (teleadministration).

b. Health consultation services and medical services that could even include surgical operations (tele-health and tele-medicine).

c. Educational services, for primary and secondary education but also for higher-university education (tele-education).

d. Vocational opportunities related to intellectual activities (teleemployment).

e. Purchasing and commercial transaction opportunities (e-commerce).

\section{An example of pilot action}

As an implementation example the following case study can be mentioned: In the framework of the Archi-Med Programme (of article 10 of the European Regional Development Fund), a telematic network ('interegionet') has been developed for the exchange of information and know how on spatial and environmental matters between the islands of the Aegean and Ionian Sea and in a second stage between all island and maritime regions of Euro-Mediterranean countries (International telematic network for interregional, transboundary and transnational cooperation and participatory planning on integrated management of coastal and island regions). 
The Network was established by the Center of the Euro-Mediterranean Regions for the Environment (KEPEMEP Med Regio) that possesses the required hardware and software for its operation [4,5]. The experience gained so far from the functioning of the network indicates the great need for its establishment, due to the significant lack of information and planning for the promotion of joint development initiatives.

The constant -on line- connection of the various focal points of the network creates coherence in the planning and implementation of all development activities within the island regions concerned. Certainly the role a planner could play within such a context is quite different -but not less important- from his role in the past. Individual action combined with collective initiatives released by means of advanced communication technologies would rather reinforce all planning processes. This is related to our capacity to know what kind of social organization we envisage and what use of technology we will make in the future.

\section{References}

[1] Castells, M. The rise of Network Society, 1996

[2] Kolodny E.Y, La population des iles de la Grece, 1974

[3] MITROPOULOS MIT: Communication Technology and the Organization of Space in Ekistics 320-1, Sept-Dec 1986

[4] Med-Regio KEPEMEP, Mediterranean CoastNet, http//www.kepemepcree.org/CoastalNet). 2001

[5] Ministry Of Environment Spatial Planning And Public Works: The Enhancement of the Environment as a Factor of Development in the Mediterranean Space, 2001

[6] Ministry Of Environment Spatial Planning And Public Works: Strategic Action Plan for the Management and the Sustainable Development of Mountainous Areas in Greece, University of Thessaly, 2000.

[7] Ministry Of Environment Spatial Planning And Public Works: Coastal Zone Management and Planning in Greece, University of Thessaly, 2000.

[8] Carraud M.- Servoin F.(eds) Le tourisme de montagne a l' heure europeenne, Collection 'Debats', Presses Universitaires de Grenoble (PUG), 2001. 